\title{
MÉTODOS DE PREPARAÇÃo E ATIVIDADE BIOLÓGICA DO ÁCIDO QUINOLÍNICO E DERIVADOS
}

\author{
Marcus Vinícius Nora de Souza*, Mauro Vieira de Almeida, Mireille Le Hyaric, Sílvia Helena Cardoso e Giovanni Wilson \\ Amarante \\ Departamento de Química, Universidade Federal de Juiz de Fora, 36036-330 Juiz de Fora-MG
}

Recebido em 14/6/02; aceito em 27/1/03

\begin{abstract}
METHODS OF PREPARATION AND BIOLOGICAL ACTIVITY OF QUINOLINIC ACID AND DERIVATIVES. In 1981 2,3pyridine dicarboxylic acid (quinolinic acid) was discovery to be a selective agonist for the $N$-methyl -D-aspartic acid (NMDA) receptor. As a consequence it possesses neurotoxic activity resulting from overstimulation of the receptor. Quinolinic acid is implicated as an etiological factor in a range of neurodegenerative disease including AIDS related dementia, Huntington's disease and Lyme disease. In the design of novel therapies to treat these diseases, some molecules have been identified as an important target. In this paper we described different methods to prepare quinolinic acid and derivatives.
\end{abstract}

Keywords: quinolinic acid; NMDA receptor; AIDS related dementia.

\section{INTRODUÇÃO}

Mais de um terço dos pacientes infectados pelo HIV sofrem de problemas neurológicos. Os sintomas incluem deficiência cognitiva e motora, conhecido como "AIDS dementia complex", mielopatia, neuropatia periférica e disfunções visuais ${ }^{1}$. A proporção de pacientes que sofrem de tais sintomas tende a aumentar à medida que as infecções oportunistas progridem. Segundo a maioria dos especialistas, uma vacina preventiva anti-HIV ou ainda um medicamento ideal é um objetivo a longo prazo e, todavia, incerto, sendo portanto necessário encontrar meios de curar os graves efeitos cognitivos associados à infecção causada pelo HIV. Este artigo aborda um suposto mecanismo da neurotoxicidade ligada ao HIV, assim como métodos de preparação do ácido quinolínico e de alguns de seus derivados, visando a prevenção ou a diminuição dos problemas cognitivos e motores provocados pelo HIV.

\section{Mecanismo da neurotoxidade associada à infecção pelo HIV}

Os problemas neurológicos associados ao HIV aparecem mesmo na ausência de infecções oportunistas e não são consequiências de uma infecção direta dos neurônios pelo $\mathrm{HIV}^{2}$. Como se pode constatar a destruição ou danos dos neurônios no decorrer da doença, conclui-se que existe a liberação de um ou mais agente(s) neurotóxico(s) pelas células infectadas. Supõe-se que um destes agentes neurotóxicos seja o ácido quinolínico 6 (Esquema 1). Este composto endogênico, produto da degradação enzimática do triptofano 1, é de concentração particularmente elevada no líquido céfaloraquidiano de pacientes portadores da AIDS $^{3}$.

Além desta evidência, o aumento da taxa de ácido quinolínico resulta em um forte aumento da taxa de cálcio nos neurônios, devido à sua interação direta ou indireta com o receptor ácido- $N$-metil-Daspártico (NMDA) ${ }^{4-6}$, uma das sub-classes dos receptores do glutamato no cérebro.

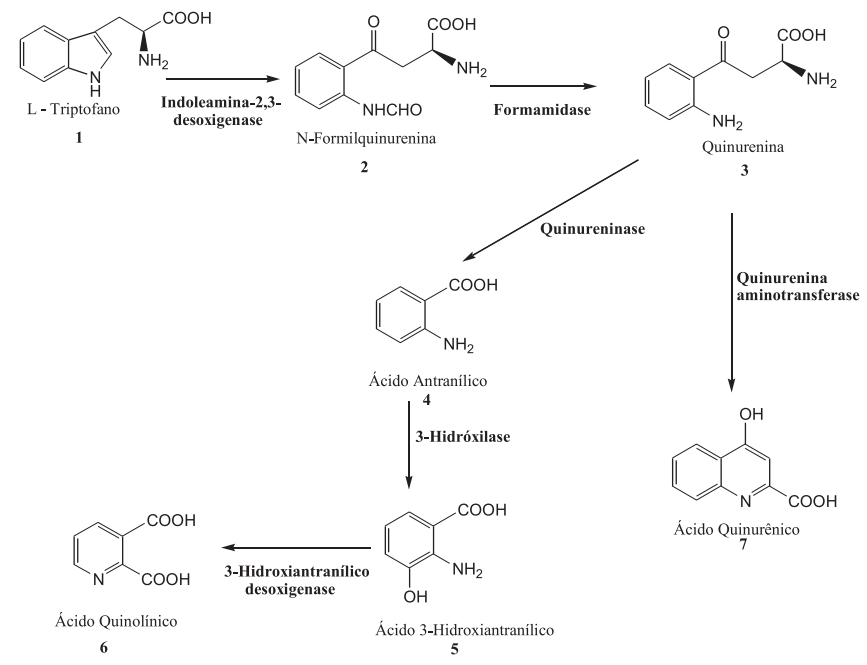

Esquema 1. Biossíntese do ácido quinolínico a partir do triptofano

\section{Receptores do glutamato}

O ácido L-glutâmico 7 é o principal neurotransmissor do sistema nervoso central dos mamíferos ${ }^{7}$. É reconhecido atualmente que o glutamato atua sobre pelo menos três classes diferentes de receptores $^{8}$. Estas sub-classes foram evidenciadas devido à descoberta de agonistas e antagonistas seletivos para cada uma delas. Estes receptores são os seguintes:

1- ácido N-metil-D-aspártico (NMDA) 8 (Figura 1);

2- ácido quisquálico 9 e, mais recentemente, o AMPA 10 (Figura 1); 3- ácido kaínico 11 (Figura 1).

Entre estes três receptores ionotrópicos do glutamato, o receptor NMDA 8 é o mais estudado. Os receptores do glutamato estão implicados em processos fisiológicos fundamentais, tais como os fenômenos de plasticidade sináptica e de memória9. É também conhecido que os aminoácidos excitadores podem causar efeitos neurotóxicos; estas moléculas provocam uma degenerescência neuronal em razão de uma liberação excessiva de cálcio ${ }^{10}$.

Assim, com base na hipótese dos efeitos neurotoxicológicos ligados a uma superprodução do ácido quinolínico, que atua sobre o 


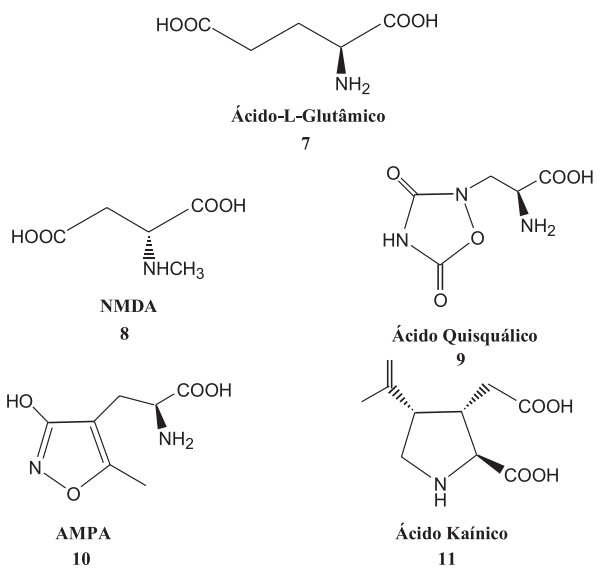

Figura 1. Receptores ionotrópicos do glutamato

receptor NMDA, a síntese de novas moléculas capazes de inibir uma dessas enzimas, impedindo assim a formação deste ácido, poderia ter um valor terapêutico no tratamento ou na prevenção de demência associada à infecção pelo HIV. Pesquisas estão em desenvolvimento nesta área ${ }^{11}$. Por exemplo, foi constatado que o derivado 4-cloro do ácido 3-hidroxiantranílico 5 é um inibidor da 3-hidroxiantranílico desoxigenase (Esquema 1) e diminui efetivamente a taxa do ácido quinolínico no líquido céfalo-raquidiano ${ }^{12}$. Um outro exemplo, a nicotinilalanina, um inibidor da quinureninase, inibe completamente o aumento da taxa do ácido quinolínico no cérebro de ratos tratados com toxinas bacterianas. Finalmente, foi demonstrado que certos derivados da classe de $\beta$-carbolinas como, por exemplo, a 6-flúor$\beta$-carbolina-3-carboxilato de metila (Figura 2), são potentes inibidores não competitivos da indoleamina-2,3-desoxigenase ${ }^{13}$.

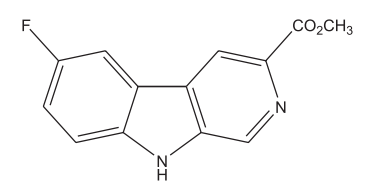

Figura 2. 6-flúor- $\beta$-carbolina-3-carboxilato de metila, um potente inibidor não competitivo da indoleamina-2,3-desoxigenase

Pode-se resumir as lesões neuronais associadas ao HIV da seguinte forma: os problemas neurológicos progressivos constatados na grande maioria de pessoas infectadas pelo HIV (soropositivos assintomáticos ou não) são mais prováveis devido à presença do vírus em certas células não neuronais do cérebro (macrófagos e astrócitos), que uma infecção oportunista devido à uma diminuição do sistema imunitário. Já que o HIV não infecta os neurônios e constatamos a destruição dos mesmos durante o curso da doença, é necessária a liberação de um ou mais agentes neurotóxicos pelas células infectadas (os macrófagos). Acredita-se que um desses possíveis agentes seja o ácido quinolínico, produto de degradação enzimática do triptofano $\mathbf{1}$, cuja concentração é fortemente aumentada nos macrófagos infectados.

A neurotoxicidade de uma ou outra destas moléculas será o resultado de um forte aumento da taxa de cálcio nos neurônios, devido à sua interação direta ou indireta com o receptor NMDA. Estas constatações sugerem que é possível prevenir ou diminuir os problemas cognitivos e motores provocados pelo HIV pela administração, seja de um antagonista do receptor do NMDA, seja de um inibidor de uma das enzimas envolvidas na transformação do triptofano 1 em ácido quinolínico 6.

\section{MÉTODOS DE PREPARAÇÃO DE ANÁLOGOS DOS ÁCIDOS QUINOLÍNICO E HOMOQUINOLÍNICO E DE DERIVADOS}

O ácido homoquinolínico 12, assim como o ácido quinolínico 6 , é um agonista do receptor do NMDA, no entanto, possuindo uma afinidade muito mais importante conforme constatado por Carvalho e colaboradores ${ }^{14}$ (Figura 3).<smiles>O=C(O)c1cccnc1C(=O)O</smiles>

Ácido Quinolínico

6<smiles>O=C(O)Cc1cccnc1C(=O)O</smiles>

Ácido Homoquinolínico

12
Figura 3. Ácido quinolínico e homoquinolínico, agonistas do receptor do NMDA

Os métodos de preparação dos ácidos quinolínico 6 e homoquinolínico 12 e de seus derivados são antigos, $\operatorname{limitados}^{15} \mathrm{e}$ poucos análogos foram até hoje sintetizados, sendo uma classe de compostos ainda pouco estudada.

\section{Métodos de preparação do ácido quinolínico}

Os métodos de preparação do ácido quinolínico 6 são, na grande maioria, baseados na utilização de quinolinas como matéria prima. Por exemplo, a oxidação da 8-hidroxiquinolina $\mathbf{1 3}$ pelo ácido nítrico a $0{ }^{\circ} \mathrm{C}$, durante $1 \mathrm{~h}$, permite a formação do ácido quinolínico $\mathbf{6} \mathrm{com}$ um rendimento quantitativo ${ }^{16,17}$ (Esquema 2).

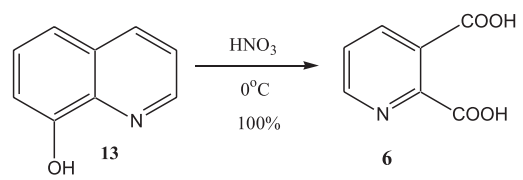

Esquema 2. Preparação do ácido quinolínico a partir da 8-hidroxiquinolina 13

A ozonólise da quinolina $\mathbf{1 4}$ permite igualmente a obtenção do ácido quinolínico com rendimento de $84 \%{ }^{18}$ (Esquema 3).

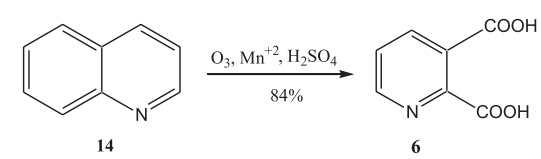

Esquema 3. Preparação do ácido quinolínico a partir da quinolina 14

Um último método empregado com sucesso é a oxidação da 2,3 dimetilpiridina 15 pelo $\mathrm{KMnO}_{4}$. O ácido quinolínico 6 pode então ser obtido com um rendimento de $82 \%{ }^{19}$ (Esquema 4).

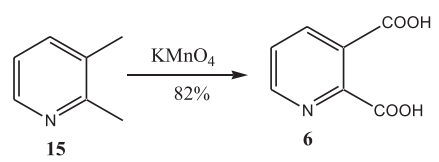

Esquema 4. Preparação do ácido quinolínico a partir da 2,3 dimetilpiridina 15 
Métodos de preparação de derivados do ácido quinolínico substituídos em posição C-4

O método geralmente empregado na síntese de derivados do ácido quinolínico 6 substituídos em posição C-4 continua sendo a reação de oxidação de quinolinas do tipo 16, substituídas nesta posição ${ }^{20}$ (Esquema 5)

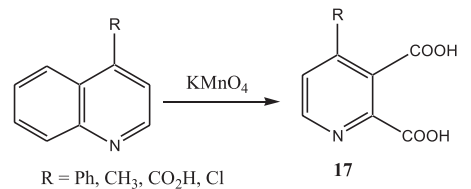

Esquema 5. Preparação de ácidos quinolínicos substituídos em posição C-4

Um outro exemplo de preparação de ácido quinolínico substituído em posição C-4 é a obtenção do triácido 19 pela oxidação com $\mathrm{KMnO}_{4}$ da 2,3,4 trimetilpiridina 18 (Esquema 6) ${ }^{21}$.

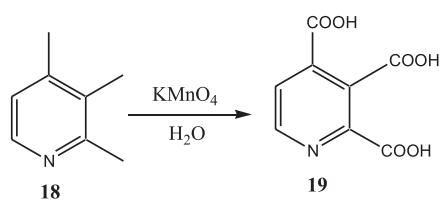

Esquema 6. Utilização da 2,3,4 trimetilpiridina 18 na preparação do triácido 19

O composto 22, um derivado do ácido quinolínico contendo na posição C-4 um grupo amina, foi isolado por Shirahama e colaboradores a partir de um cogumelo tóxico Citocybe acromelalga, proveniente do Japão ${ }^{22}$. A estrutura deste produto foi confirmada pela sua síntese, que teve como material de partida o $N$-óxido da 2,3 dimetil4-nitropiridina $\mathbf{2 0}^{22}$. A redução deste último, com ferro em ácido acético, permitiu obter o composto aminado $\mathbf{2 1}$ com um rendimento de $56 \%$. A acetilação deste produto, seguida da oxidação com $\mathrm{KMnO}_{4}$ e hidrólise ácida da acetamida formada, produziu o composto $\mathbf{2 2}$ com rendimento de 7,3\% (Esquema 7).

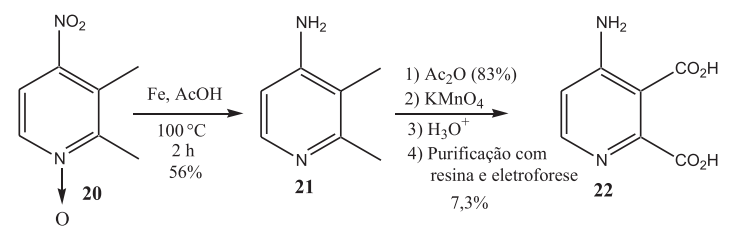

Esquema 7. Síntese de 22, composto isolado a partir de um cogumelo japonês

\section{Métodos de preparação do ácido homoquinolínico}

Os métodos de preparação do ácido homoquinolínico 12 são ainda mais raros que os do ácido quinolínico 6. O ácido homoquinolínico 12 foi sintetizado pela primeira vez por Miescher e Kagi ${ }^{23}$, pela reação do cloreto de ácido $\mathbf{2 3}$ com diazometano, conduzindo à formação do derivado 24 com rendimento de $51 \%$. O tratamento deste composto com metanol e óxido de prata (I) (reação de Ardmst-Eistert) forneceu, após rearranjo, o diéster metílico do ácido homoquinolínico 25 com $70 \%$ de rendimento. Finalmente, a saponificação do diéster produziu o ácido homoquinolínico 12 com rendimento de $77 \%$ (Esquema 8).

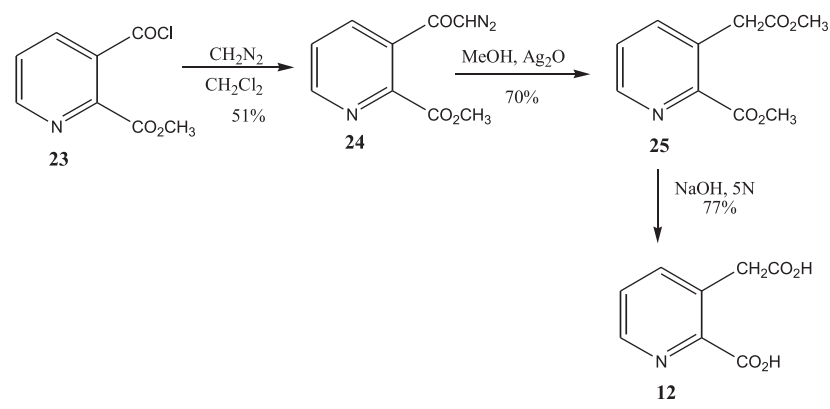

Esquema 8. Preparação do ácido homoquinolínico a partir de 23

Um outro método de preparação do ácido homoquinolínico $\mathbf{1 2}$ consiste na condensação de compostos $\beta$-dicarbonilados com halopiridinas-2-carboxilatos $\mathbf{2 6}$ em presença de sais de cobre ${ }^{24}$. O diester etílico do ácido homoquinolínico 27 foi obtido segundo este processo com rendimento de $24 \%$ (Esquema 9).

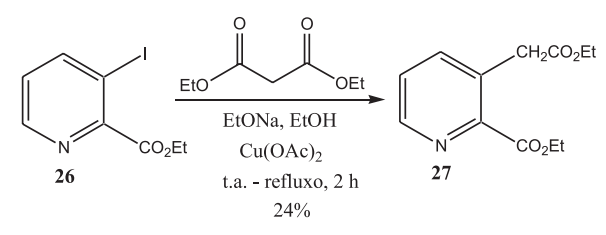

Esquema 9. Preparação do diéster etílico do ácido homoquinolínico a partir de 26

\section{Métodos de preparação de derivados do ácido homoquinolínico substituído nas posições C-5 e C-6}

Ésteres do ácido homoquinolínico substituídos em posição C-5 e C-6 foram obtidos por Tamura e colaboradores ${ }^{25,26}$, utilizando reações de ciclização de Diels-Alder. A condensação de hidrazonas do tipo 28 com o 1,3-bis-(aliloxicarbonil) aleno 29 como dienófilo conduziu à formação de derivados do ácido homoquinolínico C-5 e/ou C-6 substituídos 30 (Esquema 10).

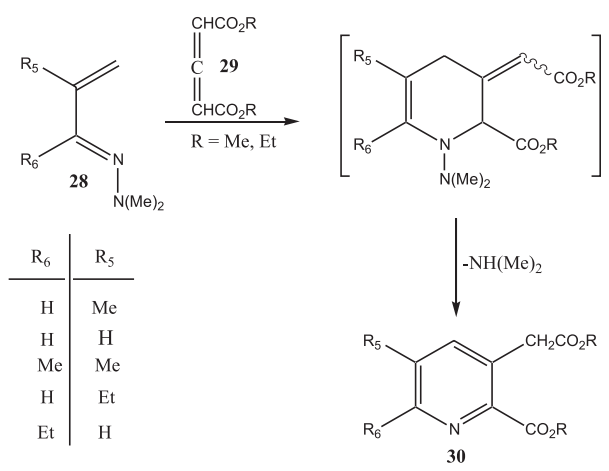

\begin{tabular}{l|c|c|c}
$\mathrm{R}_{6}$ & $\mathrm{R}_{5}$ & $\mathrm{R}$ & Rendimento (\%) \\
\hline $\mathrm{H}$ & $\mathrm{Me}$ & $\mathrm{Me}$ & 39 \\
$\mathrm{Me}$ & $\mathrm{H}$ & $\mathrm{Me}$ & 31 \\
$\mathrm{H}$ & $\mathrm{Me}$ & $\mathrm{Et}$ & 49 \\
$\mathrm{Me}$ & $\mathrm{H}$ & $\mathrm{Et}$ & 45 \\
$\mathrm{Me}$ & $\mathrm{Me}$ & $\mathrm{Et}$ & 35 \\
$\mathrm{H}$ & $\mathrm{Et}$ & $\mathrm{Et}$ & 52 \\
$\mathrm{Et}$ & $\mathrm{H}$ & $\mathrm{Et}$ & 35
\end{tabular}

Esquema 10. Preparação de ácidos homoquinolínicos substituídos em C-5 elou $C-6$ 
Nosso grupo de pesquisa foi o primeiro a desenvolver uma metodologia totalmente original para a obtenção de derivados do ácido homoquinolínico substituído em posição C-427-29 (Esquema 11). Utilizamos como material de partida o ácido picolínico 31, que foi primeiramente tratado com cloreto de tionila, com posterior adição da amina (anilina) conduzindo ao derivado clorado 32. Este derivado foi submetido à reação de ortomelação, utilizando-se como base o LDA e como eletrófilo o iodeto de metila, que permitiu a introdução do grupo metila em posição C-3 fornecendo o intermediário 33. A formação da ligação C-C foi realizada em presença de LDA e cloroformiato de etila como eletrófilo, conduzindo ao composto $\mathbf{3 4}$, análogo protegido do ácido homoquinolínico substituído em posição C-4. A síntese de outros derivados do ácido homoquinolínico preparados pelo nosso grupo será descrita em publicação posterior.

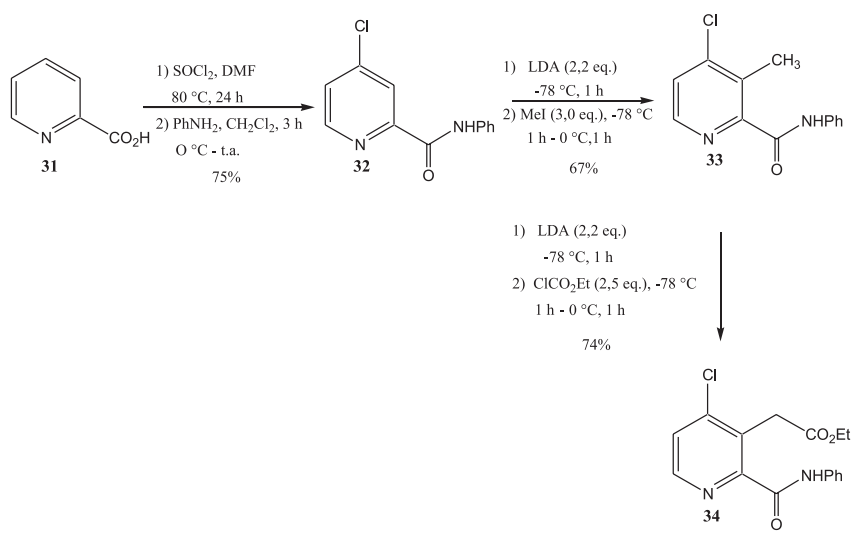

Esquema 11. Metodologia original para a obtenção de derivados do ácido homoquinolínico substituídos em posição $C$-4

\section{USO DO ÁCIDO QUINOLÍNICO COMO LIGANTE E MATERIAL DE PARTIDA}

O ácido quinolínico 6 tem sido utilizado como ligante na preparação de complexos de rutênio(III) ${ }^{30}$ visando a preparação de antibacterianos e antitumorais. Outros tipos de complexos de alumínio(III $)^{31}$, manganês(I $)^{32}$, európio ${ }^{33,34}$ e térbio $^{34}$, envolvendo este mesmo ligante, têm sido preparados com diferentes finalidades. $\mathrm{O}$ ácido quinolínico pode também ser usado como material de partida na preparação de outras classes de substâncias ${ }^{35}$. Um exemplo é a síntese das quinolinimidas 35 e $\mathbf{3 6}^{36}$ (Esquema 12).

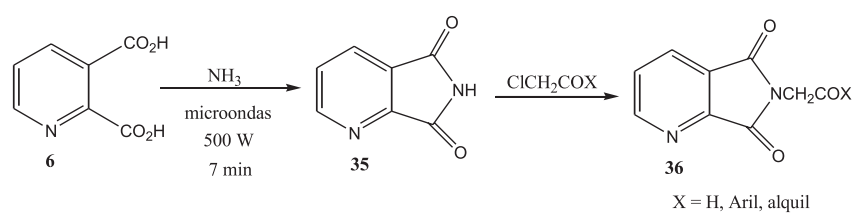

Esquema 12. Síntese de quinolinimidas tendo o ácido quinolínico como material de partida

\section{CONCLUSÃO}

Muitos estudos químicos e biológicos têm sido realizados visando uma maior compreensão dos problemas neurológicos associados ao HIV, os quais possibilitariam o desenvolvimento de novas vias terapêuticas capazes de prevenir ou diminuir esta neurotoxicidade.
Tais estudos permitiram relacionar os efeitos neurotoxicológicos ligados a uma superprodução do ácido quinolínico. Desta forma, a síntese de novas moléculas capazes de inibir uma das enzimas, impedindo assim a formação deste ácido, poderia ter um importante valor terapêutico. Apesar da importância biológica dos ácidos quinolínico e homoquinolínico e de seus derivados, existem poucas metodologias descritas atualmente na literatura para suas preparações sendo, portanto, um campo promissor para novas pesquisas científicas.

\section{AGRADECIMENTOS}

Os autores agradecem à FAPEMIG e ao CNPq pelas bolsas concedidas.

\section{REFERÊNCIAS}

1. Price, R. W.; Brew, B.; Sidtis, J. J.; Science 1988, 239, 586; Sidtis, J. J.; Price, R. W.; Neurology 1990, 40, 323; Lipton, S. A.; Nature 1994, 367, 113.

2. Koenig, S.; Gendelman, H. E.; Science 1986, 233, 1089.

3. Heyes, M. P.; Brew, B. J.; Ann. Neurol. 1991, 29, 202.

4. Patneau, D. K.; Mayer, M. L.; J. Neurosci. 1990, 10, 2385; Petersen, A.; Chase, K.; Puschban, Z.; DiFiglia, M.; Brundin, P.; Aronin, N.; Exp. Neurol. 2002, 175, 297.

5. Stone, T. W.; Perkins, M. N.; Eur. J. Pharmacol. 1981, 72, 411.

6. Perkins, M. N.; Stone, T. W.; J. Pharmacol. Exp. Ther. 1983, 226, 511.

7. Hayashi; T.; J. Jpn. Physiol. 1952, 3, 46.

8. Nakanashi, S.; Science 1992, 258, 597.

9. Collingridge, G. L.; Singer, W.; Trends Pharmacol. Sci. 1990, 11, 290.

10. Rothman, S. M.; J. Neurosci. 1984, 4, 1984.

11. Kita, T.; Morrison, P. F.; Heyes, M. P.; J. Neurochem. 2002, 82, 258; Pawlak, D.; Tankiewicz, A.; Mysliwiec, P.; Buczko, W.; Nephron. 2002, 90, 328; Chiarugi, A.; Calvani, M.; Meli, E.; Traggiai, E.; Moroni, F.; Neuroimmunol. 2001, 120, 190; Chiarugi, A.; Meli, E.; Moroni, F.; J. Neurochem. 2001, 77, 1310.

12. Lehmann, J.; Randle, J. C. R.; Reynolds, I. J.; Trends Pharmacol. Sci. 1990, 11,1 .

13. Peterson, A. C.; LaLoggia, A. J.; Med. Chem. Res. 1993, 3, 473.

14. De Carvalho, P. L.; Bocher, P. J.; J. Neurochem. 1996, 28, 445; Grimwood, S.; Wafford, K.; Macaulay, A.; Hutson, P.; J. Neurochem. 2002, 82, 794.

15. Skramp, D.; Monatsh. Chem. 1881, 2, 157; Fischer, O.; Renouf, H.; Chem. Ber. 1884, 17, 755; Riedel, H.; US pat. DE 945147 1945; Kulka, M.; J. Am. Chem. Soc. 1946, 68, 2472; Akhmerova, S. G.; Islamgulova, V. R.; Koksharov, V. G.; Sapozhnikov, Y. E.; Manaeva, R. M.; Zh. Bash. Khim. 2001, 8, 9 .

16. Suchard, M.; Chem. Ber. 1925, 58, 1728.

17. Dornow, A.; Schacht, W.; Chem. Ber. 1947, 80, 507.

18. Tyupalo, N. F.; Semenyuk, T. N.; Kolbasina, O. I.; Zh. Fiz. Khim. 1992, 66, 871; Giselbrecht, K.; Perndorfer, E.; Reiter, K.; Eur. Pat. Appl. 1052253 2000.

19. Garret, S.; J. Chem. Soc. 1903, 83, 76.

20. Koenigs, F.; Chem. Ber. 1879, 12, 983; Koenigs, F.; Chem. Ber. 1881, 14, 103; Hoogewerff, D.; Chem. Ber. 1880, 13, 1640; Hoogewerff, D.; Chem. Ber. 1880, 13, 152; Koesch, P.; Steinhaem, K.; J. Org. Chem. 1953, 18, 1516.

21. Oparina, M. P.; Chem. Ber: 1931, 64, 569.

22. Hirayama, F.; Konno, K.; Shirahama, H.; Matsumoto, T.; Phytochemistry 1989, 28, 1133.

23. Miescher, K.; Kagi, H.; Helv. Chim. Acta 1941, 24, 1471.

24. Ames, D. E.; J. Chem. Soc., Perkin Trans. 1 1972, 705.

25. Tamura, Y.; Tsugoshi, T.; Nakaiyama, Y.; Kita, Y.; Synthesis 1984, 930.

26. Tamura, Y.; Tsugoshi, T.; Chem. Pharm. Bull. 1985, 33, 3257.

27. Souza, M.V. N.; Tese de Doutorado, Université Paris XI, France, 1999.

28. Souza, M.V. N.; Dodd, R. H.; Heterocycles 1998, 47, 811.

29. Souza, M. V. N.; Almeida, M. V.; Quim. Nova 2001, 25, 89.

30. Sengupta, P.; Dinda, R.; Ghosh, S.; Guha, A. K.; Transition Met. Chem. 2002, 27, 290; Sengupta, P.; Ghosh, S.; Mak, T. C. W.; Polyhedron 2001, $20,975$.

31. Loring, J. S.; Karlsson, M.; Fawcett, W. R.; Casey, W. H.; Polyhedron 2001, $20,975$.

32. Maurya, R. C.; Batalia, S.; Indian J. Chem., Sect. A: Inorg., Bio-inorg., Phys., Theor. Anal. Chem. 2001, 40, 652. 
33. Zolin, V. F.; Puntus, L. N.; Kudryashova, V. A.; Tsaryuk, V.; Legendziewicz, J.; Gawryszewska, P.; Szostak, R.; J. Alloys Compd. 2002, 341, 376; Kalinovskaya, I. V.; Karasev, V. E.; Efimova, N. V.; Lifar, L. I.; Russ. J. Inorg. Chem. 2002, 47, 212; Puntus, L. N; Zolin, V. F.; Kudryashova, V. A.; Tsaryuk, V.; Legendziewicz, J.; Gawryszewska, P.; Szostak, R.; Phys. Solid State 2002, 44, 1440
34. Kalinovskaya, I. V.; Karasev, V. E.; Efimova, N. V.; Lifar, L. I.; Russ. J. Inorg. Chem. 2002, 47, 72.

35. Saound, M.; Benabdelouahab, F. B.; Guemmount, F.; Romerosa, A. M.; Heterocycl. Commun. 2001, 7, 439; Bahajaj, A. A.; Vernon, J. M.; Wilson, G. D.; J. Chem. Soc., Perkin Trans. 1 2001, 12, 1446.

36. Blanco, M. M.; Perillo, L. A.; Schapira, C. B.; Molecules 2000, 5, 481. 